\title{
Consensus Ad Idem: A Plea for Objectivity in Telephonic Contracts
}

\author{
D Ganesh Kumar* and Akshay Douglas Gudinho ${ }^{+}$
}

\section{Abstract}

Consensus Ad Idem, legally defined as 'meeting of minds', at the time of the formation of a contract, warrants a cardinal jurisprudential question which transcends its mere literal meaning. In Indian Contract Law, the trend has followed the test of objectivity, whereby it is not the actual intent of the party or parties that enter into the contract that is the subject of judicial evaluation, but it is what a reasonable man would deliberate in the peculiar circumstances of the case. However, the evaluation of telephonic conversations merit intrinsic jurisprudential insight. While applying the objective test, the questions that arise are - is there legal certainty of assent to a contract over telephonic conversations i.e. whether there is free consent. Do the parties have the capacity to contract over telephone? What are the liabilities of the telephone operator and his legal bond to the contract between two or more contracting parties? Does it amount to violation of the fundamental rights to freedom of speech and expression and the right to privacy? The authors attempt to provide an objective analysis of communication in contracts over telephonic means and the constitutional environment embedded therein. To this end, a plea for due diligence prior to the formation of telephonic contracts shall be made in order to bring

* Symbiosis Law School, Pune, India; dgk@symlaw.ac.in

† Symbiosis Law School, Pune, India; akshay.gudinho@symlaw.ac.in 
objectivity to the judicial evaluation of telephonic contracts.

Keywords: Contracts, Information Technology Act 2000, Liabilities, Objective Test, Right to Privacy, Telephonic Contract, Consensus Ad Idem

\section{Introduction}

The Honourable Supreme Court of India in the case of Bhagwandas Goverdhandas Kedia v. M/S. Girdharilal Parshottamdas ${ }^{1}$ has held that at the time of drafting the Indian Contract Act in 1872, instantaneous means of communication such as the telephone was not known while drafting the sections dealing with communication.

Section 4 of the Indian Contract Act is a corollary of the above statement, as it reads:

"Communication when complete - The
communication of a proposal is complete when it
comes to the knowledge of the person to whom it is
made.
The communication of an acceptance is complete, as
against the proposer, when it is put in a course of
transmission to him so as to be out of the power of
the acceptor; as against the acceptor, when it comes
to the knowledge of the proposer."

As the above provision is devoid of any specification with regard to the modes of transmission of proposals or acceptances, certain exceptions have been drawn in favour of the laws governing communications of Indian contracts. Regarding an offer and its acceptance, Anson ${ }^{2}$ has given an analogy of a lighted match stick. "Acceptance is to an offer what a lighted match is to a train of gunpowder. It produces something which can't be recalled or undone." An acceptance turns the offer into a binding obligation.

1 Bhagwandas Goverdhandas Kedia v. M/S. Girdharilal Parshottamdas, AIR 1966 SC 543.

2 JACK BEATSON, ANDREW BURROWS \& JOHN CARTWRIGHT, ANSON'S LAW OF CONTRACT (Oxford University Press, London, 29th ed., 2010). 
In case of contracts made via telegraph, the contract is complete where the acceptance is made and not where it is received. ${ }^{3}$ As acceptance and not an offer is the subject that gives rise to a cause of action 4 , the contract in case of telegraph is completed, even before it comes to the knowledge of the proposer, as long as the acceptor has put his assent in transmission beyond his control. The reason for this exception drawn in favour of telegram can be encapsulated by words of Hidayatullah J. in the Kedia ${ }^{5}$ case:

The rule about lost letters of acceptance was made out of expediency because it was easier in commercial circles to prove the dispatch of letters but very difficult to disprove a statement that the letter was not received.

Similarly, the Allahabad High Court has applied the postal rule even to email communication. ${ }^{6}$ Further, Section 13(1) of the Information Technology Act, 2000 holds that the dispatch of an electronic record occurs when it enters a computer source outside the control of the originator. This implies that a contract via email is enforceable once it is sent out of the control of the offeree.

However, the postal rule does not apply in case of telephonic contracts. In the Kedia judgment, the majority held that as both the parties had clear communication of the offer and the acceptance of the contract, the same was deemed to be completed where the proposer received the knowledge of the assent by the acceptor and not by the mere transmission of the assent via telephonic dispatch. The court held that since the dispatch of acceptance via telephone is instantaneous with no third party intervention i.e. the postal department, it is analogous to contracts made in physical presence. Though this holds as a sound judgement, an acceptance over a telephonic conversation cannot be marred by loss in signals, environmental disturbances, and the like. The question that begs

\footnotetext{
${ }^{3}$ American Pipe Co. v. State of U.P., AIR 1983 Cal 186.

${ }^{4}$ Republic Medico Surgical Co. v. UOI, AIR 1980 Karn 168.

${ }^{5}$ Supra note 1.

${ }^{6}$ PR Transport v. UOI, AIR 2006 All 23.

${ }^{7}$ Supra note 1.
} 
attention is, whether the telephonic contract has been assented to without free consent or in the absence of knowledge regarding the capacity of the parties. As there is such a limited time frame between the transmission of assent and its receipt by the proposer, there is hardly any scope for evaluation of the circumstances the acceptor may be placed in, or the devious means of contracting the offeror / offeree may adopt at the time of contracting.

The Kedia ${ }^{8}$ Judgment itself was decreed on the understanding that there was utmost clarity in communication between the contracting parties. However, does mere clarity of speech encapsulate the legal yardsticks of contracts over the telephone? Is Vou et praeterea nihil viz. a voice and nothing more, a valid legal proof of evidence to a contract over the telephone? Is it legally justified for the offeror to hear the assent of the offeree even in case of the risk of the telephone lines being severed? The fallacies that these questions highlight are that, the instantaneous mode of telephonic contracts should not negate the postal rule merely due to the transmission between the offeror and the offeree having no lapse of time.

\section{The Objective Test under Indian Contract Law}

According to the Indian Contract Act, 1872 "An Agreement enforceable by law is a contract". 9 The process begins with a proposal to obtain the assent of another to an act or abstinence. ${ }^{10}$ The proposal when accepted becomes a promise. ${ }^{11}$ The person making the proposal is the 'promisor', and the person accepting the proposal is the 'promisee'.12 The act or abstinence related to a promise is called the consideration for the promise. ${ }^{13}$ The promise may be expressed or implied. ${ }^{14}$ The promise or every set of promises that forms the consideration for each other, is an

\footnotetext{
8 Supra note 1.

${ }^{9}$ Indian Contract Act, 1872, § 2 (h).

${ }^{10} \mathrm{Id}$ at $\S 2$ (a).

${ }^{11} \mathrm{Id}$. at $\S 2$ (b).

$12 \mathrm{Id}$. at $\S 2$ (c).

${ }^{13} I d$. at $\S 2(\mathrm{~d})$.

$14 \mathrm{Id}$. at $\S 9$. 
agreement. ${ }^{15}$ An agreement becomes a contract when it is made by the free consent of parties competent to contract, for a lawful consideration, with a lawful object, and if the contract is not being expressly declared as void. ${ }^{16}$

With regard to telephonic contracts, the High Court of Madhya Pradesh has held that, if, during the conversation the telephone lines go 'dead' so that the offerer does not hear the offeree's word of acceptance, there is no contract at that moment. ${ }^{17}$ It is quite evident that the question of implied offers over telephones does not arise, as there is no evaluation of one's conduct. But, yet again the question of evidence has been answered by mere clarity of speech. Does free consent, capacity of the parties, and lawful consideration, emerge from an authentic recording? The lack of elaboration with regard to telephonic contracts which are expressly declared as void or which contain an illegal object is because the evidence for the same is a statutory or judicial declaration/ pronouncement. Thus, the feasibility of such evidence is present in the written law itself.

In case of contracts made in person, a valid consideration is the test that determines whether a contract has taken place or not. ${ }^{18} \mathrm{~A}$ valid consideration is the price of the promise ${ }^{19}$, without which, the performance of any promise is nothing but lip service. In Chappell $\mathcal{E}$ Co. Ltd v. Nestle Co. $\mathrm{Ltd}^{20}{ }^{20}$ it was held that a "peppercorn does not cease to be good consideration if it is established that the promisee does not like pepper and will throw away the corn." In India, the courts have even applied the principle of implied consideration, whereby, a voluntary service done in the past implies the need for payment. ${ }^{21}$ Section 25 of the Indian Contract Act itself forbids any agreement without consideration unless it is in writing and

\footnotetext{
${ }^{15} \mathrm{Id}$. at $\S 2(\mathrm{e})$.

16 Id. at $\S 10$.

${ }^{17}$ Kanhaiyala J v. Dineshwarchandra, AIR 1959 M.P. 234.

${ }^{18}$ CWT v. Abdul Hussain Mulla Muhammad Ali, (1988) 3 SCC 562.

${ }^{19}$ SIR FREDERICK POLLOCK, POLLOCK ON CONTRACTS 133 (LexisNexis $13^{\text {th }}$ ed. 2012).

${ }^{20}$ Chappell \& Co. Ltd v. Nestle Co. Ltd., 1960 AC 87.

21 Upton-on-Severn RDC v. Powell, (1942) 1 All ER 220.
} 
registered, made on account of natural love or affection; is a promise to compensate for something done as a past service or is a promise to pay a time barred debt, i.e., a debt barred by the law of limitation.

The legal malady encountered in case of telephonic contracts is that even if the consideration is agreed to be paid on performance of the promise of the promisor, there emerges a lack of evidence to prove the existence of the agreement unless, the conversation is recorded. In the absence of a recording, the courts will rely on the evidence of consideration which, in itself, does not definitively prove the existence of an agreement as there is lack of physical documents to ascertain the same. The Supreme Court, however, apart from the presence of an agreement and a valid consideration, has adopted a third parameter for the evaluation of the existence of a contract i.e. the intention to create Vinculum jurie or a legal bond or relation.

Here it is not the mere intention of either of the parties, but their intention to create legal relations. ${ }^{22}$ The difference between the two lies in the fact that the former is a subjective cognitive expression of the parties at the time of the formation of the contract, while the latter provides rights to either of the parties even in the absence of the narration of such rights. A cardinal case of contracts that is exemplar of the objective test is the Lalman Shukla v. Gauri Dutt ${ }^{23}$, decided by the Allahabad High Court. Here, the servant i.e. the plaintiff in the case was not permitted to recover the award from the defendant on finding his lost nephew, as he claimed the reward, after finding the boy. Thus, by applying the objective test, his initial intention was not to gain the reward notified by the defendant, but to return the boy. As the defendant had explicitly offered to provide Rs. 501/- by handbills to anyone who found the boy, the right to claim the award would emerge only if one had accepted the offer first. Thus, it is an objective and not a subjective test that the Indian courts apply, as has been evolved and developed in England. ${ }^{24}$

\footnotetext{
22 Supra note 1.

${ }^{23}$ Lalman Shukla v. Gauri Dutt, (1913) 11 All LJ 489.

24 Supra note 21.
} 


\section{Novel Instruments of Objectivity}

The determination of speech amounting to an objective evaluation of an intention to create legal relations in telephonic contracts, is fraught with challenges. With regard to free consent, under section 13 of the Indian Contract Act, 1872 there is no objective evaluation of whether the consent/offer over the telephone has been obtained by coercion, undue influence, fraud, misrepresentation or mistake. Even if the aggrieved party decides to make the contract voidable under section 19 or section 19-A of the Indian Contract Act, the burden of proof on the plaintiff to prove the aforementioned parameters against free consent is as high as that of criminal law with regards to proof beyond a reasonable doubt. ${ }^{25}$ Thus, the argument boils down to the most feasible means of evidential material that can bring certainty that there was free assent or a valid offer and thereby a valid intention to create legal relations.

The Supreme Court of India has held recording of conversations that are valid to the material facts of the case, as admissible evidence under section 7 of the Indian Evidence Act. ${ }^{26}$ The Supreme Court has given further guidelines that the voice of the speaker on the recorded evidence must be clearly identifiable, audible and clear. In the absence of which, the recorded evidence would be subject to strict proof. ${ }^{27}$ However, apart from authenticity and clarity of the recorded conversation, the Supreme Court of India has not laid down any guidelines for the strict proof of identity of the contracting parties over the telephone. Further, does the authentic recording of the conversation amount to a valid evidence to prove the existence of a contract?

A recording in isolation is no ground to definitively prove the capacity of the parties or whether there was free consent. Further, the recording of a conversation is not a statutory requirement in case of telephonic contracts as it is considered as a contract made in physical presence under Section 4 of the Indian Contract Act, 1872. This leaves the evidence of recording in the hands of the parties

\footnotetext{
${ }^{25}$ Krishna Wanti v. LIC, AIR 2000 Del 63.

${ }^{26}$ R.M. Malkani v. State of Maharashtra, (1973) 1 SCC 471.

27 Ram Singh v. Col. Ram Singh, 1985 Supp SCC 611.
} 
themselves, which opens the gates for the tampering of evidential material. It should be noted that the Supreme Court does not permit a tampered recording as valid evidence in the court of law ${ }^{28}$. However, this does not prevent the parties of the contract from committing the act, thereby vitiating the validity of a sound evidence for contracts over the telephone.

With respect to contracts via email, section 12 of the Information Technology Act, 2000 provides for a receipt of acknowledgment of the electronic record sent by the originator to the addressee. In the absence of which, the contract fails to be binding. This brings an element of reasonable due diligence on part of the originator and the addressee to ensure the certainty of the receipt of the acknowledgment of the details of the contract. Thereafter, if an assent is given, it is presumed that the addressee has assented to all the terms in the contract because he had previously sent an acknowledgement to the originator with regards to the receipt of his offer. Section 65-B of the said Act permits the admissibility of an electronic record in case of a court proceeding. Here, the receipt of acknowledgment too can be received without free consent or without ascertaining the consent of the parties. However, the said Act has ensured a prior step of due diligence of evidence to create a legal whetting system to avoid voidability. In this regard, the court, while evaluating the circumstances may rely on the receipt of acknowledgement as valid evidence to prove that there was intention to create legal relations devoid of the subjective circumstances. However, in case of telephonic contracts, apart from recording of the contractual conversation, the question that merits attention is whether the testimony of a witness to a telephonic conversation or a telephone operator himself can act as valid evidence to the existence of the oral contract that took place. As far as contractual laws in India are concerned, the question remains unsettled apart from the mere application of section 4 of the Indian Contract Act to telephonic contracts and the clarity of speech over the telephone amounting to a valid assent/offer. 
The Honourable court of Kentucky had confronted the issue in the Sullivan v. Kuykendall ${ }^{29}$ case. The court held that if a person asks the operator to repeat his message to a third person, he is bound by the words of the operator, even though he does not consent with the instructions given at a later point of time. Here, the operator was held to be the agent of the person giving the instructions and his testimony was not held to be mere hearsay evidence. Expanding the Kuykendall 30 case, as there was a third party intervention, there emerges a reasonable due diligence undertaken by the offeror or offeree because in such a case, the operator can act as a witness of the conversation that had taken place. Further, in People v. Ward, ${ }^{31}$ a criminal case, the court held that the fact that the witness, in his testimony, was able to identify the prisoner/defendant over the phone along with the second witness' testimony, who was standing six inches away from the first witness, amounted to a valid evidence of identification. The legal loophole that arises here is that mimicry is not taken into consideration if the person receiving the information via the telephone identifies the voice under the guise of it being somebody else's. This provides not only an undue advantage to the witness who provides the evidence but also resorts the test of objectivity to a subjective and biased witness.

\section{Recommendations}

The platform for strengthening objectivity in telephonic contracts is to have a certain amount of prior due diligence undertaking, by all the contracting parties so that in case of a breach, an objective provision of valid evidence is present. To this end, a third party impartial witness to all telephonic contracts or detailed guidelines for recording, must be laid down by the Supreme Court. This, however, should not be considered as a panacea for all breaches of telephonic contracts. Contracts over all electronic means are always subject to and prone to fraudulent activities. But, the state, in the least can ensure evidential mechanisms to create a whetting system prior to the formation of the contract.

${ }^{29}$ Sullivan v. Kuykendall, 82 Ky., 483.

${ }^{30} \mathrm{Id}$.

${ }^{31}$ People v. Ward, 3 N. Y. Crim. Rep. 483, 511. 
To this end, a mechanism whereby the telephone operator can ensure the capacity of the parties before the contract fructifies can be a fruitful and legally concrete exercise in order to avoid voidability. However, ascertaining the capacity of the parties over the telephone without documents authenticating the same renders our suggestions to only a third party entity bearing witness to the telephonic conversation that forms the contract. This might amount to hearsay evidence. In this regard, the telephone operator can in the least serve as a vigilance system weeding out the parties that are not competent to contract before the formation of the contract. For this, the operator must contain a repository of information regarding both parties derived from Aadhaar card information or any of the like kind. In effect, every party contracting over the telephone would have to have a registered document of identity with the Government to assure their competency to contract. Further, it is imperative that the postal rule be applied even to telephonic contracts as the operator can ensure as a matter of evidence that the assent was sent rather than the offeror proving that he received it by the telephone operator.

\section{Right to Privacy}

With regard to the above recommendations, certain constitutional questions must be brought to the fore. The third party intervention raises the question of the right to privacy, as a contract between two or more private individuals and is a matter that should be devoid of state intervention. However, the right to privacy has been held not to be an absolute right and is subject to reasonable restrictions. ${ }^{32}$ With regards to recording, section 5(2) of the Indian Telegraph Act, 1885, permits the Government to intercept any telegraphic messages in times of public emergency. The section has even been applied to telephonic interceptions by the Government. In 1997, the Supreme Court while maintaining phone tapping as a serious invasion of the right to privacy, upheld the constitutionality of the aforementioned section..$^{33}$ Following the strict guidelines laid down by the court, the Central Government passed a notification in

\footnotetext{
32 Supra note 4.

${ }^{33}$ People's Union of Civil Liberties v. UOI, AIR 1997 SC 568. 
2007 amending the rule 419 of the Indian Telegraph Rules, 1951, and adding rule $419 \mathrm{~A}$. The said amendment brought certain levels of vigilance before the authorisation of phone tapping.

As per the amendment, a requisition of interception can be sent only by the two appointed nodal officers in each law enforcement agency, who cannot be under the rank of a Superintendent or additional superintendent of Police. Further, such an order for interception can only come from the Secretary to the Government of India in the Ministry of Home Affairs, or from the Secretary of the State Government, in-charge of the Home Department or the Joint Secretary to the Government of India, in case of unavoidable circumstances. A receipt of requisition by a law enforcement agency is to be handled by two senior executives of the company of the service provider, who are to act as nodal officers in the designated area. An acknowledgment receipt must be provided to the law enforcement agency within two hours of the receipt of the said requisition.

A Review Committee comprising of the Cabinet Secretary as the Chairman, Secretary to the Government of India in-charge, Legal Affairs, and Secretary to the Government of India, Department of Telecommunications, was also instituted. A State review body comprising of analogous positions has also been established. Lastly, guidelines of recording of reasons for interceptions, internal whetting mechanisms for checking unauthorized interceptions, and permissibility of tapping only when all other means are exhausted have also been made. ${ }^{34}$

At the outset, it should be noted that if the parties have consented to the recording by the third party Governmental agency, then the question of right to privacy does not arise as this is a voluntary provision for disclosure of information. However, to provide a recommendation for all telephonic contracts to have a state entity as a third party witness, necessarily implies that the Government must intervene in every contract. If the consideration is with regards to contracts made with the Government, then it implies

${ }^{34}$ Ministry of communications and information technology, Government of India, http://www.dot.gov.in/sites/ default/files/ march 2007.pdf, (last visited on April 22,2017). 
violation of right to privacy, as this serves as a prior establishment of evidence in case of a potential breach. However, in case of private contracts, the question arises as to whether such Governmental interference is permissible. If not, the argument with regards to the right to privacy remains pertinent.

One of the established cardinal principle is that, if the public interest warrants, and the transaction is of public nature, as in the case of public Corporations or Bodies, whether such Corporation or Body is funded and controlled by the State or not, then public interest outweighs private interest. Hence, one argument in favour of the Government is that in case of any public emergency, such a recording can be justified with respect to the aforementioned amendment. However, as a public emergency is not a pre-requisite to any contract or an event that is always at the Government's disposal, state intervention for the purpose of evidential material to strengthen the objectivity of Consensus Ad Idem over telephonic contracts must be deliberated upon.

It is a matter of settled law that a fundamental right exists only against the state and not private individuals. ${ }^{35}$ However, the courts have intervened in a multitude of cases where there have been serious violations of fundamental rights by private individuals and have broadened the definition of 'State' under Article 12. ${ }^{36}$ The line of argument in majority of the cases is that state inaction cannot escape the liability of the violation of a fundamental right. The same line of thought is followed with respect to criminal cases whereby the victim is represented by the state. However, such an intervention is justified only if the gravity of the crime violates a fundamental right. Hence, the applicability of phone tapping is only in cases of public emergency and when all other means are exhausted.

To adopt the strict guidelines of the 2007 notification regarding recording of telephonic conversations that lead to the formation of contracts is to protect the person from voidability itself. To this end,

${ }^{35}$ P.D. Shamdasani v. Central Bank of India, AIR 1952 SC 59.

36 People's Union for Democratic Rights v. Union of India, (1982) 3 S.C.C.235; Maneka Gandhi v. UOI, AIR 1978 SC 597; Olga Tellis v. Bombay Municipal Corporation, 1986 AIR 180. 
every contract over the telephone would be ironclad thereby making business more feasible. Under the Telecom Regulation Authority of India (TRAI) Act 1997, section 12 provides TRAI the powers to conduct investigations and to call for information with regards to service providers/ telephone operators. The said section does not deal with recording of conversation.

However, if a contract is completed but the lines are severed, the liability may come upon the service provider. But, such liability can be evaded by establishment of due diligence by the service provider that the recording of the conversation between the contracting parties were available to the same. Thus, in case of a breach, the operator will not be held liable or legally bound as either of the parties had the option of obtaining the recording for the purpose of declaring their contract voidable. In this regard the service provider would only be a distributor of information and not a publisher. ${ }^{37}$ Further, under Section 12 (4) of the said act, the authority has the power to issue such directions to service providers as it may consider necessary for proper functioning by them. If a direction is given by TRAI with regards to recording, they have the defence of avoiding liability in case of lines being severed, even in case of private contracts, as every telephone operator, be it public or private, is under TRAI regulations. Thus, such Governmental interference has precedence over the right to privacy as soon as the parties contracted have assented to such interference over the telephone for the want of evidential material on their part and the exemption of liability on part of the Government. In this regard, it has to be noted that the legislature should employ nodal agencies in case of all contracts made over the telephone. Even in the absence of intra-nodal agencies in companies or firms, there should be a nodal agency that can be communicated with, during the formation of the contract over the telephone so that the parties can ensure that their contract is devoid of any ambiguity. With respect to the postal rule, such an agency can hold as evidence that the assent was indeed sent to the offeror.

37 Cubby Inc v. Compuserve Inc., 776 F Supp 13; Zeran v. America Online Inc 129 F $3 d 327$. 
With respect to jurisdiction of the court, the place at which the assent is sent, shall preside, if a cause of action shall arise. To this end, it is imperative that at the time of the formation of the contract, the nodal agency where the offeree resides must be contacted for the purpose of territorial and evidential feasibility. In case the telephone lines are severed, the representative of such nodal agency can appear as a witness to the same. A legislation that requires the authentication and legal compulsion of a recording in case of telephonic contracts will in itself be a mechanism to prove consensus ad idem. If such a mechanism is established, it mitigates the clarity of one's speech being the only evidence towards the establishment of a contract over the telephone. Once such legislation is passed, it becomes immaterial if the consent to such a recording was given or whether one's right to privacy is infringed or not, as it would amount to the ignorance of the law. In effect, there would be a mutuality of obligation on part of both the contracting parties to ensure the evidence of their conversation and also the legal justification for the power and authority to enter into such a contractual obligation. In effect, there is a hybrid of double due diligence, where not only is the conversation to the contract recorded but also the operator ascertains the authenticity of the same.

As per Section 107 of the Uniform Computer Information Transaction Act (CITA), 2002, a uniform Act passed by the National Conference of Commissioners on Uniform State Laws in the United States, a party to a contract is given the autonomy, in any transaction, to establish requirements regarding the authentication or record acceptable to the same. Further, even if the other party is unaware of such a record, he is bound by the electronic agent used. The particular section, however, does permit the tampering of a recording to be binding on the party not aware of it. In avoidance of the same, in case of the establishment of the nodal agencies, TRAI itself can function as a review body in matters of tampering of the evidence. In this way, every party contracting over the telephone would give up their right to privacy for the want of evidence material, which TRAI can be permitted to investigate under Section 12. 


\section{Conclusion}

In the light of the arguments presented, the authors feel that Section 12 of the TRAI Act, 1997 should be amended, to include, recording by service providers of telephonic conversations dealing with contracts. Alternatively, the Law Commission should recommend, or the Supreme Court should take suo motto cognizance, and lay detailed guidelines and direct the legislature to initiate steps to come out with a lucid legislation on the subject matter. The ultimate implication would be that the recording of the telephonic conversation that leads to the formation of a contract would become a pre-requisite to all contracts entered through this mode or channel, rather than it being an initiative taken by one of the contracting parties. 